\title{
Relações Sociais de Sexo e Psicodinâmica do Trabalho: a sexuação das defesas no trabalho de care

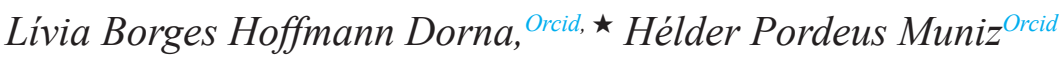 \\ Universidade Federal Fluminense, Niterói, RJ, Brasil
}

\begin{abstract}
Resumo
Este artigo se propõe a apresentar algumas pesquisas analisadas por Pascale Molinier acerca dos sistemas defensivos contra o sofrimento no trabalho de care. Para ela, se as situações de trabalho que produzem sofrimento não são as mesmas para homens e mulheres, os sofrimentos e, consequentemente os sistemas defensivos para lidar com eles, serão sexuados - alguns são masculinos, outros femininos. Sob o ângulo combinado da Psicodinâmica do Trabalho e das Relações Sociais de Sexo, as pesquisas de Molinier permitem demonstrar que esta tendência à "sexuação" das defesas se dá não em função da "natureza" dos homens e das mulheres, e sim em decorrência da divisão sexual do trabalho. Estas pesquisas evidenciam ainda que certas modalidades da subjetividade classicamente atribuídas à constelação psíquica da feminilidade são, em grande parte, diferenciações contingentes e secundárias à experiência do trabalho.Palavras-chave: Relações Sociais de Sexo; Psicodinâmica do Trabalho; sistemas defensivos; trabalho de care.
\end{abstract}

Palavras-chave: Relações Sociais de Sexo; Psicodinâmica do Trabalho; sistemas defensivos; trabalho de care.

\section{Sex Social Relationships and Psychodynamics of Work: the sexuation of the defenses in caring labour}

\begin{abstract}
This article aims to present some research analyzed by Pascale Molinier on defense strategies against suffering at caring labor. Under her perspective, if the work situations that produce suffering are not the same for men and women, the sufferings and consequently the defense systems to deal with them will be distinct regarding sex - some are masculine, some feminine.Under the combined perspective of Psychodynamics of Work and Sex Social Relationships, these researches allow to demonstrate a tendency to the "sexuation" of the defenses, not because of the "nature" of men and women, but because of the sexual division of work. These studies provided evidence that the modalities of subjectivation classically attributed to the psychic constellation of femininity are mostly contingent diferentiations and secondary to the experience of work.
\end{abstract}

Keywords: Sex Social Relationships; Psychodynamics of Work; defensive systems; caring labor.

\section{Introdução}

A Psicodinâmica do Trabalho (PDT) edificou-se a partir das ideias e pesquisas de Christophe Dejours acerca das relações entre saúde mental e trabalho, iniciadas nos anos 1970. Inicialmente enquadrado na tradição da Psicopatologia do Trabalho, Dejours centrava seu interesse em pesquisas, observações e descrições dos distúrbios psicopatológicos provocados pelas vicissitudes do trabalho.

Os estudos de situações concretas de trabalho o levaram, no entanto, a questionar o modelo psicopatológico causal: os trabalhadores não eram passivos ante os constrangimentos organizacionais, conseguindo, em sua maioria, esconjurar a loucura. A problemática de Dejours é então submetida a uma reviravolta epistemológica: o interesse se desloca para a normalidade, tida como um enigma - como os trabalhadores resistem às pressões psíquicas do trabalho e, apesar delas, não enlouquecem?

Ao operar a passagem da patologia à normalidade, Dejours amplia a perspectiva deste campo de atuação, que passa a ocupar-se da "análise psicodinâmica dos processos intersubjetivos mobilizados pelas situações de trabalho" (DEJOURS, 2008, p. 51), e, em consequência, recebe uma nova nomenclatura: Psicodinâmica do Trabalho.

\footnotetext{
^Endereço para correspondência: Universidade Federal Fluminense, Instituto de Psicologia, Campus do Gragoatá. Rua Professor Marcos Waldemar de Freitas Reis, $\mathrm{s} / \mathrm{n}^{\circ}$, Bloco N, $4^{\circ}$ andar. São Domingos - Niterói, RJ - Brasil. CEP: 24210 201.E-mail: liviahoffmann@gmail.com, heldermuniz@uol.com.br
}

A escola dejouriana, desde o início, constituiu-se a partir de articulações entre diversos especialistas, mantendo sempre o diálogo com as ciências da saúde (incluindo aí a psicanálise) e com as ciências do trabalho, com a incorporação, em especial, das contribuições da Ergonomia (DEJOURS, 2008).

A partir de 1988, ocasião em que ocorreu o seminário Plaisir et souffrance dans le travail, iniciou-se um importante trabalho interdisciplinar entre a Psicodinâmica do Trabalho e as sociologias do trabalho. Na origem da articulação entre estes dois campos está o questionamento de Danièle Kergoat e Helena Hirata endereçado à Dejours: considerando que os fundamentos teóricos e as primeiras descobertas empíricas da PDT foram estabelecidas em um quadro de referência ao masculino-neutro, esta abordagem seria adequada para compreender também a relação saúde mental-trabalho nas situações vividas pelas mulheres? "As relações sociais de sexo representavam o nó cego da psicodinâmica do trabalho" (MOLINIER, 2004, p. 16).

Ao consideramos a problemática das relações sociais de sexo como transversal ao conjunto do campo social, e, portanto, ao conjunto dos campos disciplinares (HIRATA; KERGOAT, 1988), a divisão sexual do trabalho passa a ocupar um lugar central na pesquisa clínica, na teoria e na metodologia em psicodinâmica do trabalho. 
A partir da categorização de classe e sexo, os sociólogos do trabalho colocam em questão todo um arcabouço teórico da psicanálise que considerava que as diferenças psíquicas entre homens e mulheres tinham sua origem na idade precoce da psicossexualidade, bem antes do encontro com o trabalho (MOLINIER, 2004). "As relações entre a economia erótica (o sexual) e as determinações sociais da diferença dos sexos (o sexuado) são dinâmicas" (MOLINIER, 2002, p. 2, tradução nossa).

Assim, a problemática do prazer e do sofrimento no trabalho vem sendo construída em proveito de uma concepção dinâmica das relações entre sujeito e sociedade (MOLINIER, 2004). Isto requer, ao mesmo tempo: recusar o "impasse sobre o peso dos determinismos sociais e seu heteronômio com relação à psicologia individual" (MOLINIER, 2004, p. 17); não ceder à tentação de uma ciência do homem sem subjetividade, um sujeito reduzido a "um simples reflexo do social, uma marionete sem espessura psíquica" (MOLINIER, 2004, p. 17).

O trabalho, desafio central da PDT e das sociologias do trabalho, e a doutrina comum das relações entre determinismos e liberdade, tornaram possível um trabalho interdisciplinar fecundo.

Cabe lembrar, no entanto, que o campo aberto pela discussão entre a psicodinâmica do trabalho e a sociologia das relações sociais de sexo não é homogêneo do ponto de vista teórico. Entre a aparelhagem conceitual da PDT e aquela das ciências sociais, existem recobrimentos semânticos que podem levar à confusão (MOLINIER, 2002). O conceito de identidade é um exemplo disto.

\section{Identidade, Trabalho e Relações Sociais de Sexo}

Para as ciências sociais, as identidades são coletivas. O termo "identidade sexuada" vai assim designar o pertencimento a um grupo definido pelo seu gênero (masculinidade e feminilidade), enquanto que o termo "identidade sexual" designa o pertencimento a um grupo em função da sua orientação sexual (MOLINIER, 2002).

Para a PDT, a identidade, ao contrário, é singular e pode ser definida como uma busca do sentimento de unidade da personalidade e como sentimento de continuidade desta unidade.

O termo identidade sexual também tem um significado diferente daquele da sociologia, fazendo referência à sexualidade psíquica e ao corpo erótico. Esboçada na infância, a identidade sexual não é entendida como um dado invariante, estável, e não conflitante - ela será colocada em questão pelas primeiras experiências amorosas e também, de maneira decisiva, pela experiência de trabalho (MOLINIER, 2004). Assim, a identidade é uma luta, uma conquista - ela precisa ser reconfirmada sem cessar, essencialmente pelo olhar do outro, através de duas dinâmicas distintas: a dinâmica da realização de si mesmo na esfera erótica (com destaque para o amor) e a dinâmica de realização de si mesmo na esfera social (com destaque para o trabalho de produção). É nesse sentido que Dejours (2012) vai postular uma dupla centralidade - da sexualidade e do trabalho - na construção da identidade.
Por se indexar no olhar do outro, a identidade precisa passar por formas de objetivação - e a obra é a forma mais poderosa de objetivação da identidade. Mas nós não temos os mesmos talentos, nem as mesmas condições sociais de acesso à realização de obras. A conquista da identidade remete, portanto, às relações sociais - é preciso considerar na sua construção a dinâmica da contradição, do antagonismo entre os grupos sociais, sem perder de vista que se trata de "uma contradição viva, perpetuamente em vias de modificação, de recriação" (KERGOAT, 1986, p. 82).

No que tange especificamente às relações sociais de sexo, Kergoat (2009) nos ensina que elas têm características singulares: se encontram em todas as sociedades conhecidas e são estruturantes para o conjunto do campo social e transversais à totalidade deste campo.

Como todas as relações sociais, as relações sociais de sexo têm uma base material, e não apenas ideológica: o trabalho. O grupo social de homens e o grupo social de mulheres estão em tensão permanente em torno do trabalho e suas divisões. Existe, portanto, uma divisão sexual do trabalho, que opera a partir de dois princípios organizadores: o princípio de separação, segundo o qual existem trabalhos de homens e trabalhos de mulheres; e o princípio de hierarquização - um trabalho de homem "vale" mais do que um trabalho de mulher (KERGOAT, 2009).

Estes princípios podem ser aplicados graças a um processo específico de legitimação - a ideologia naturalista, que rebaixa o gênero ao sexo biológico, reduzindo as práticas sociais a papéis sociais sexuados, que por sua vez remetem a um destino natural da espécie (KERGOAT, 2009).

O cuidado e a preocupação com os outros e tudo aquilo que remete às necessidades e ao padecimento dos corpos, às doenças e ao envelhecimento são assim designados prioritariamente às mulheres e confundidos com a feminilidade no sentido social do termo. Submersas na "essência feminina", essas obras são pouco visíveis e pouco valorizadas.

Para Dejours (2012), esse trabalho de desvelo remete ao confronto afetivo com as falências do corpo - e tudo que ele pode produzir em termos de receios, angústias, aversões e desgostos pelo sofrimento, pelas dores, pelas feiuras, dejeções, odores - e provoca, portanto, "a angústia ante a perenidade do próprio corpo" (DEJOURS, 2012, p. 170). Os homens, segundo ele, atribuem às mulheres o trabalho de desvelo como forma de não enfrentarem a dolorosa percepção que o confronto afetivo com o corpo do outro provoca.

Pelo mesmo movimento, negam as competências da disponibilidade, do tato, da compaixão necessária para enfrentar a situação, pois pressupõem o reconhecimento do real e a insuficiência da ciência. Completam este ato de negação pela naturalização dessas competências, que declaram absolutamente femininas, como bem o mostraram Danièle Kergoat e Helena Hirata (DEJOURS, 2012, p. 170). 
Trata-se daquilo que Molinier (2004) define como "naturalização do trabalho compassivo na feminilidade social". Assim, as mulheres, em geral, em função de suas atividades, podem menos facilmente ignorar o real da vulnerabilidade dos corpos (MOLINIER, 2002).

\section{Sofrimento e sistemas defensivos}

Para a Psicodinâmica do Trabalho o sofrimento é inevitável e compatível com a normalidade e com a salvaguarda do equilíbrio psíquico, mas implica uma série de mecanismos de regulação. Trata-se assim de uma concepção dinâmica do sofrimento: entre as pressões do trabalho e a doença mental encontra-se um indivíduo capaz de compreender, reagir e se defender de determinada situação.

Ainda que o sofrimento seja uma vivência subjetiva e remeta, portanto, a um sujeito singular, as pesquisas em PDT têm demonstrado como a dimensão coletiva do trabalho é particularmente importante para a construção da saúde no trabalho. A análise dos processos psíquicos mobilizados pelo encontro entre o trabalhador e os constrangimentos da organização do trabalho tem demonstrado que existem formas de cooperação defensiva que permitem lutar contra os efeitos desestabilizadores e patogênicos do trabalho, e que são construídas, organizadas e gerenciadas coletivamente (DEJOURS; ABDOUCHELI, 1994).

A diferença fundamental entre uma estratégia coletiva de defesa e os mecanismos de defesa individual é que a primeira se estrutura em torno da construção de um consenso, a ser sustentado por todos. Assim, quando se integra um coletivo, aprende-se rápido que existem coisas sobre as quais não se deve falar, condutas que devem ser evitadas e outras que, ao contrário, são recomendadas: "integrar-se a uma equipe de trabalho implica poder aderir às suas estratégias coletivas de defesa" (MOLINIER, 2002, p. 4, tradução nossa).

As pesquisas de Pascale Molinier irão analisar as incidências da divisão sexual do trabalho sobre a subjetividade, e sobre a construção desses sistemas defensivos. Para ela, se as situações de trabalho que produzem sofrimento não são as mesmas para homens e mulheres, os sofrimentos e, consequentemente os sistemas defensivos para lidar com eles, serão, portanto, sexuados - alguns são masculinos, outros femininos (MOLINIER, 2004). Apresentaremos a seguir algumas pesquisas sobre os sistemas defensivos engendrados por homens e mulheres para lidar com o sofrimento no trabalho de care. ${ }^{1}$

\section{Virilidade e Masculinidade}

Em um coletivo de homens que exerce um trabalho arriscado, não é recomendado dizer ou mostrar que se tem medo. Ao contrário: é preciso dar aos outros provas de coragem e bravura. Trata-se, na realidade, de "lutar contra o medo gerado pelo trabalho opondo coletivamente uma recusa de sua percepção" (MOLINIER, 2004, p.

\footnotetext{
Algumas autoras francesas preferem utilizar o termo inglês care, por acreditarem que o termo soin (cuidado em francês) possui uma excessiva conotação terapêutica. Para Molinier, os termos solicitude ou devotamento seriam igualmente inadequados porque esconderiam a ideia fundamental de que a preocupação pelo outro implica trabalho. O termo care, segundo ela, inclui a ideia de um trabalho social. Manteremos nesse artigo o termo em inglês utilizado por esta autora.
}

17). A negação do sofrimento masculino repousa no consenso segundo o qual os homens não devem exprimir o sofrimento (MOLINIER, 1996).

$\mathrm{Na}$ construção desta recusa, a virilidade social é fundamental. É importante ressaltar que virilidade e masculinidade não são sinônimos. A masculinidade seria a identidade sexual, enquanto a virilidade designa um conjunto de condutas, estereótipos e valores a partir dos quais um indivíduo é reconhecido como pertencente ao grupo dos homens.

Um verdadeiro homem deve dominar e desprezar o medo. Aquele que não tem sucesso em fazê-lo é um fraco, um afeminado, uma mulher, já que a vulnerabilidade, a passividade, o medo, a sensibilidade são versados socialmente no registro do feminino. O homem que sofre deve se calar ou partir, do contrário está exposto à provocações, humilhações e até mesmo à violência física.

A adesão à estratégia defensiva é, então, vetorizada pelo desejo de se integrar à equipe e, conjuntamente, ser reconhecido e apreciado pelos outros homens como um deles, se beneficiando assim da proteção conferida pelas defesas contra os sofrimentos do trabalho. O sistema viril é necessário à auto conservação, mas repousa sobre o conformismo/ submissão ao sistema de valores da virilidade: a periculosidade e a penosidade da tarefa passam a ser valorizadas e não questionadas com vistas à transformação (MOLINIER, 1996).

Além disso, Dejours demonstrou que a virilidade não anestesia apenas a percepção do medo, mas também o sentido moral e é usada pelos homens para justificar a sua participação na injustiça social. "Em nome da coragem viril, o mal feito pelos homens é mais facilmente justificado que aquele cometido pelas mulheres" (MOLINIER, 2004, p. 18). Nesse sentido, a virilidade contraria o exercício da autonomia moral subjetiva: trabalhar pode implicar realizar atos que constituem prejuízos à dignidade das pessoas e as transgressões podem ser valorizadas como condutas viris.

Considerando que, quando se inicia no mundo do trabalho é comum que o sujeito não esteja suficiente maduro e seguro de sua identidade sexual, no encontro com os constrangimentos deletérios das situações de trabalho, o risco de captura da identidade masculina pela virilidade defensiva é real (MOLINIER, 2004). Nesse sentido, a virilidade social pode funcionar como uma identidade de empréstimo naquilo que ela promete de valorização (MOLINIER, 1996).

\section{Mulhebridade e Feminilidade}

Do lado das mulheres, Dejours criou o neologismo mulheridade ou mulhebridade para designar o estatuto de submissão conferido às mulheres nas relações sociais de sexo. A mulhebridade traduz-se na prática por um conjunto de condutas através das quais uma mulher comporta-se de acordo com este estatuto de submissão para evitar represálias (MOLINIER, 2002).

Fractal, Rev. Psicol., v. 30 - n. 2, p. 154-160, 2018 
Assim como a virilidade, a mulhebridade é uma identidade defensiva de sexo. Mas ao contrário do que ocorre com a virilidade, ela não serve bem como identidade de empréstimo porque não é valorizada - só leva à depreciação de si. Nesse sentido, trata-se de uma estratégia de defesa menos promissora do que a virilidade. A única exceção à pejoração do feminino é a maternidade: a abnegação e o sacrifício materno participam da construção social de dominação das mulheres. Transposta ao mundo do trabalho remunerado, a maternidade social transforma-se em uma prescrição à compaixão: a mulher seria, por natureza, uma mãe para todos os seres humanos (MOLINIER, 1996).

A mulhebridade é ainda conservadora da hierarquia entre os sexos e serve aos interesses defensivos da virilidade.

Se as condutas e atitudes das mulheres são decretadas, em grande parte e de maneira decisiva, a partir do mundo dos homens em função do interesse destes, a conformação do sujeito-mulher às posturas da mulhebridade se opera também pela mediação do grupo de mulheres (MOLINIER, 2002, p. 5).

Quando engendrada por um grupo de mulheres, a mulhebridade consiste em punir por exclusão ou ostracismo aquelas que não se satisfazem com a condição de dominadas. Estas "rebeldes" representam para as demais o risco de revelar o sofrimento gerado pela opressão e a tomada de consciência do esforço que elas mobilizam para lidar a opressão de forma a sofrer o menos possível.

\section{Sofrimento em coletivos masculinos e sofrimento em coletivos femininos: algumas pesquisas}

As pesquisas realizadas por Joan Cassel (apud MOLINIER, 2002) sugerem como os sistemas defensivos dos cirurgiões estão escoradas na ideologia viril. Os homens, diferentemente das mulheres, têm acesso fácil aos dispositivos sociais que lhe permitem mobilizar a agressividade necessária ao gesto cirúrgico intrusivo de cortar o corpo de alguém que está vivo. Segundo ela, as cirurgiãs que não conseguirem mobilizar a sua agressividade e sadismo não poderão operar. Ao mesmo tempo, elas precisam adotar aquilo que Cassel definiu como "comportamentos adequados de gênero" para tranquilizar os homens quanto à bipolarização do mundo. Do contrário, correm o risco de serem excluídas da sala de operações. É preciso assim dar provas de sua fidelidade à feminilidade, como usar batom não pelo prazer de fazê-lo, e sim como forma de se pouparem do sofrimento de serem desprezadas como uma não-mulher.

Nesse mesmo sentido, Molinier (2002) apresenta o artigo da psicanalista Joan Rivière intitulado "A feminilidade como uma farsa", ${ }^{3}$ onde ela relata casos de mulheres que exercem atividades ditas masculinas. Dentre eles, cita o exemplo de uma "faz tudo" que se sente obrigada a dissimular seus conhecimentos técnicos e se fazer de tola e inocente na frente de empreiteiros ou tapeceiros, como forma de colocar suas sugestões e conseguir o que quer.

\footnotetext{
${ }^{2}$ Tradução nossa. Expressão original: les justes comportements de genre. ${ }^{3}$ Tradução nossa. Título original: La feminité en tant que mascarade.
}

Segundo Molinier, os trabalhos de Cassel nos ajudam a compreender que o subterfúgio da feminilidade como uma farsa não seria apenas um movimento psíquico endógeno decorrente da ressonância simbólica com o pai da história infantil, mas também mobilizado pelas imposições que os homens endereçam às mulheres que transgridem as normas de gênero. Assim, estas mulheres consentiriam em reiterar em parte essas normas, aceitando se passar por "femininas", tal como acontece no caso das cirurgiãs.

Poderíamos esperar que estas cirurgiãs, em aderência aos sistemas defensivos dos cirurgiões, se virilizassem. As pesquisas em questão demonstraram que isso não ocorre porque, ainda que sejam minoritárias na atividade de cirurgia, elas exercem seu trabalho em um meio onde as mulheres são a maioria dentre os subordinados. Nesse sentido, as cirurgiãs devem cumprir requisitos diferentes daqueles impostos aos cirurgiões: espera-se que elas deem provas de firmeza como os homens, mas que também estejam mais disponíveis à escuta dos outros. Isso porque, segundo Molinier (2002), as enfermeiras aceitam menos o autoritarismo vindo de outra mulher e tendem a fazer greve de zelo nessas circunstâncias.

Nesse sentido, ela vai afirmar que "mesmo que nas atividades 'masculinas' as mulheres trabalhem em parte diferentemente dos homens, não é sempre a primeira intenção. Mas sobretudo porque as mulheres que tentam empregar os métodos viris, aqueles que funcionam para os homens, são frequentemente a seu prejuízo e insucesso" (MOLINIER, 2004, p. 21).

Assim, para fazerem o trabalho acontecer - e para fazê-lo gerando menos sofrimento possível - estas cirurgiãs dão preferência por um tipo de gestão compreensiva ao invés de um tipo autoritário. Esta escolha não se explicaria, assim, em função de um componente intrínseco à psique feminina e sim por uma questão pragmática.

Ainda que estas formas de gestão possam ser entendidas como mais interessantes por serem respeitosas com as subordinadas, para as cirurgiãs elas são mais caras do ponto de vista psíquico, uma vez que requerem o preocupar-se com o outro. "Isso implica uma outra relação com o medo e a vulnerabilidade dos corpos. Logo, a construção de defesas sensivelmente diferentes daquelas dos homens" (MOLINIER, 2002, p. 7).

As defesas mobilizadas pelos cirurgiões para suportar e ter êxito são sustentadas, por sua vez, pelo trabalho e pelos corpos das mulheres: as enfermeiras descarregam as tensões deles ao se ajustarem às suas necessidades $e$ magnificarem os gestos dos cirurgiões. Mas a que preço para as enfermeiras? (MOLINIER, 2004)

Nesse sentido, Molinier questiona se poderíamos supor que o trabalho das enfermeiras mobilizaria defensivamente o masoquismo e se a erotização do sofrimento seria necessária para conseguir suportar as situações de trabalho.

Em uma pesquisa com enfermeiras que trabalhavam em centros cirúrgicos, Molinier (2002) relata como elas, nas falas iniciais, menosprezavam o próprio trabalho, como algo besta, banal. À medida em que avançavam, no entanto, a complexidade do seu trabalho aparecia aos 
poucos. Elas estavam longe de serem meras executantes, responsáveis "apenas" por passar os instrumentos: eram capazes de decifrar, através da observação fina do agir expressivo dos cirurgiões, sinais precursores de sua irritação, cansaço e menor vigilância, e de ajudá-los a descontrair.

O trabalho dessas enfermeiras consistia, frequentemente, em antecipar o gesto operatório do cirurgião, dando-lhe os instrumentos antes que ele os demande. Estas antecipações dos gestos eram, inclusive, um modo de transmitir discretamente aos cirurgiões menos experientes os saberes-fazer por elas observados nas intervenções realizadas por outros cirurgiões. Nesse sentido, os saberes-fazer discretos destas enfermeiras respeitavam o não-dito da virilidade (MOLINIER, 2002).

Esta acuidade perceptiva das enfermeiras era mobilizada sob o efeito do medo da cólera dos cirurgiões (trata-se de se poupar do sofrimento gerado pelas humilhações e insultos) e sobretudo, do temor dos erros que os cirurgiões pudessem cometer.

Nestas pesquisas, o coletivo de enfermagem desempenhou um papel determinante na socialização da relação entre enfermeiras e cirurgiões e do sofrimento que as aflige. Através de paródias, onde as enfermeiras imitavam os cirurgiões de forma caricatural, elas demonstravam o seu conhecimento pelo corpo, saberes indizíveis e invisíveis, que apenas o agir expressivo pode fazer aparecer: "a função catártica da paródia não pode ser reduzida somente à sua função dialógica. Nesse caso, o dito importa menos do que a paixão dos corpos" (MOLINIER, 2002, p. 10, tradução nossa).

Estas paródias colocavam também em cena as fraquezas dos cirurgiões, permitindo que eles se humanizassem e se tornassem amáveis. A relação das enfermeiras para com os cirurgiões era, assim, tingida de ambivalências. Compaixão e ternura podiam ser exprimidos a partir do momento em que as enfermeiras concordavam em "perdoar" o machismo dos cirurgiões em nome do seu saber-fazer - e desta forma transformar o ressentimento em admiração. A humanização dos cirurgiões pelo coletivo de enfermagem implicava assim um julgamento de beleza, um reconhecimento pelo trabalho cumprido.

Em acordo sobre a qualidade do trabalho dos cirurgiões, as enfermeiras se precaveem em parte do risco de serem seduzidas individualmente e, ao permitirem a admiração, a despeito do mau tratamento infligido pelos cirurgiões, elas constroem regras comuns, que definindo os limites sobre o que é tolerável em nome da eficácia, permitem estabelecer uma diferenciação entre 'a mulher' e 'a profissional' (MOLINIER, 2002, p. 10, tradução nossa).

Assim, se em um primeiro momento as enfermeiras procuravam se defender do sofrimento infligido pelos cirurgiões individualmente, buscando conter a agressividade no jogo da sedução, num segundo momento, o faziam coletivamente, através de racionalizações partilhadas que consistiam em naturalizar os excessos dos cirurgiões: eles são assim porque são homens. Na sequência, e a partir das paródias, os desculpavam e os admiravam em nome da eficácia do trabalho. Esses "privilégios" não podiam ser con- cedidos pelas enfermeiras aos cirurgiões sem, no entanto, colocar em questão os seus sistemas defensivos. Por isso a importância de elaborarem coletivamente as perturbações e embaraços que as ambivalências suscitaram.

No que diz respeito à relação entre enfermeiras e pacientes, as pesquisas de Molinier (2004) demonstram que se espera que elas sofram - seu sofrimento testemunharia a qualidade da sua presença "maternal" junto aos doentes.

A organização do trabalho hospitalar, no entanto, ancorada na virilidade social, coloca as enfermeiras diante de uma forte contradição: entre a prescrição da compaixão universal e os constrangimentos temporais, que as conduzem a deixar em segundo plano a humanização dos cuidados em relação às dimensões técnicas do trabalho. Assim, "trabalhar bem é construir o melhor compromisso entre eficácia técnica e compaixão” (MOLINIER, 2004, p. 19).

Diferentemente dos sistemas defensivos viris de negação da realidade, negar a sua própria vulnerabilidade deixaria as enfermeiras insensíveis ao sofrimento, o que colocaria em xeque a eficiência e mesmo o sentido do trabalho. Assim, a fim de manter a qualidade do trabalho e a sua própria saúde mental, as enfermeiras consagram um tempo significativo às discussões entre elas, que visam elaborar o sofrimento gerado pelo trabalho sem contrapor uma negação. Esses momentos de elaboração compõem, na realidade, estratégias coletivas de defesa das enfermeiras, mas muitas vezes são rotulados sob o estereótipo sexual da fofoca: as mulheres são fofoqueiras.

Para quem ouve de fora, o tom dessas conversas podia parecer insolente: as enfermeiras, muitas vezes, zombam dos doentes, dos chefes, dos médicos e de si mesmas, como "frágeis mulheres". "A dimensão da autoironia frente à própria vulnerabilidade é o componente essencial das defesas 'femininas"' (MOLINIER, 2004, p. 20). Se zombar da sua própria vulnerabilidade é inconcebível na perspectiva viril, ela é congruente com a feminilidade.

Trata-se de estratégias de "domesticação" do real, que tendem, no entanto, a desparecer à medida que o trabalho se intensifica e que a avaliação do trabalho se centra, não na qualidade do cuidado, e sim na prontidão em "esvaziar as camas" ou as "rentabilizar" (MOLINIER, 2004, p. 20). Nessas circunstâncias as enfermeiras têm o sentimento de realizar um trabalho indigno, vergonhoso, nefasto para o outro e incoerente com seus valores. É nesse sentido que Molinier (2004, p. 20) vai afirmar que "não é a compaixão que é patogênica, mas a impossibilidade crônica de lhe dar uma saída criativa". Entre o drama da doença e a subversão coletiva do sofrimento, são bastante comuns a "mudança" e o "ativismo" como mecanismos de defesa individuais.

Os mecanismos de mudança consistem em solicitar a troca de cargo ou de setor ou até pedir demissão, após tentativas frustradas de resistir ou modificar a situação de trabalho. Partir seria uma recusa a se tornar cúmplice do sistema. Este tipo de mecanismo frequentemente se sucede a uma fase de ativismo, que consiste em querer concluir sua tarefa integralmente, em prejuízo da sua vida pessoal e com grande esgotamento profissional. 
Explorado pela organização de trabalho, o ativismo não é reconhecido nem recompensado. Além disso, é fonte de conflito entre aquelas que trabalham sem contar suas horas, sem descanso, e aquelas que tentam resguardar sua vida privada, fazendo respeitar seus direitos. Assim, dificilmente é uma estratégia coletiva. As dificuldades e os sofrimentos relativos à "conciliação" do trabalho produtivo com o reprodutivo não são remetidos à organização do trabalho e sim às próprias enfermeiras, que não dariam conta por serem "más profissionais" e “más mães” (MOLINIER, 2004).

Cabe ainda ressaltar que as mulheres que exercem atividades ditas femininas não estão sempre na medida de reconhecer o real - há casos em que é preciso se defender de perceber o seu trabalho como degradante para a própria dignidade. É possível assim identificar, por exemplo, em certos coletivos de auxiliares de enfermagem responsáveis pela gestão dos dejetos corporais e da sujeira, ideologias defensivas da profissão denominadas Kaporalisme (MOLINIER, 1996, 2004). As ideologias defensivas são estratégias coletivas de defesa radicalizadas, que ocorrem quando não é possível construir compromissos satisfatórios com a organização do trabalho, quando a luta contra o sofrimento corrói o sentido e mesmo a eficácia do trabalho.

O Kaporalisme se baseia em uma filosofia construída sobre um duplo modelo do homem: os merecedores e os não merecedores da compaixão. Na prática, consiste em fazer uma triagem entre: os doentes que cooperam ativamente e demonstram gratidão - para estes a doença é uma injustiça e, por isso, serão tratados como pessoas sem restrições; aqueles que não manifestam gratidão e tornam as tarefas mais penosas - estes têm o que merecem e serão tratados como subprodutos da espécie humana.

Para Molinier (1996), o Kaporalisme poderia ser interpretado como uma reviravolta sobre o corpo dos pacientes das ofensas e humilhações sofridas no próprio corpo das auxiliares de enfermagem, em função dos constrangimentos do trabalho.

Esta manobra contra a perda da autoestima é devastadora para os doentes que lhe são alvo e arriscadas para aquelas que a praticam, podendo levá-las a uma dupla estigmatização: malvadas como profissionais e como mulheres (já que a indiferença e a violência seriam incompatíveis como a feminilidade).

\section{Considerações finais}

Fiéis às opções metodológicas da PDT, as pesquisas de Pascale Molinier sobre o trabalho de cuidar têm como eixo de análise o conflito entre o sujeito e os constrangimentos da organização do trabalho. Este conflito, no entanto, tem sido por ela redefinido no contexto de uma problemática que integra a divisão sexual do trabalho, considerando-a como "uma dimensão estrutural e central na relação subjetividade-trabalho" (MOLINIER, 2004).

Pensar as relações saúde e trabalho sob o ângulo combinado da psicodinâmica do trabalho e das relações sociais de sexo tem permitido compreender que, diante das vicissitudes do trabalho, existe uma "sexuação" das defesas.
Os sistemas defensivos engendrados pelos homens na luta contra o sofrimento no trabalho são organizados, tendencialmente ${ }_{2}$ em torno da negação do real e da experiência dolorosa da perda do domínio, do fracasso, da humilhação. Tratam-se, assim, de estratégias centradas na comprovação da sua virilidade. Já os sistemas defensivos das mulheres se fundam no reconhecimento do real e da experiência afetiva de fracasso a ele associada (DEJOURS, 2012).

Assim, o sistema defensivo viril não seria eficaz para certos coletivos femininos de trabalho, conforme aponta a pesquisa com cirurgiãs citada neste artigo. Para evitarem o sofrimento e fazerem o trabalho acontecer, estas mulheres preferem assumir os "comportamentos adequados de gênero" que, por sua vez, ajudam a sustentar os sistemas defensivos mobilizados pelos homens.

Importante não perdermos de vista, no entanto, que, ainda que a distância entre os grupos de sexo tenha permanecido estável, a divisão sexual do trabalho apresenta uma incrível plasticidade (HIRATA; KERGOAT, 2007). Se ela é uma dimensão estrutural e central na relação subjetividade-trabalho, há que estar atento às variações nas suas modalidades concretas e suas possíveis repercussões nos sistemas defensivos engendrados.

Acreditamos que não por acaso Dejours tenha utilizado o termo "tendencialmente" ao referir-se à organização dos sistemas defensivos masculinos e femininos. Como ressaltamos acima, não podemos desconsiderar a complexidade e as possibilidades de mudança no jogo das relações sociais - homens e mulheres sofrem a ação dessas relações, mas também agem sobre elas. Assim, as relações entre saúde mental-trabalho e a divisão sexual do trabalho não podem ser pensadas de maneira determinista - existem possibilidades de rupturas.

As pesquisas apontadas por Molinier são, entretanto, fundamentais para o entendimento de que a sexuação das defesas não ocorre em função da "natureza" dos homens e das mulheres - é preciso considerar a divisão sexual do trabalho em suas análises. Da mesma forma, estas pesquisas permitem demonstrar que certas modalidades da subjetividade, como a paciência, a receptividade e a sensibilidade à vulnerabilidade do outro (classicamente consideradas pela psicologia clínica como pertencentes à constelação psíquica da feminilidade e do "eu relacional" das mulheres) são, em grande parte, diferenciações contingentes e secundárias à experiência do trabalho (MOLINIER, 2004).

A compaixão das enfermeiras, por exemplo, comumente naturalizada e confundida com a feminilidade, é na realidade decorrente de um processo psíquico desencadeado pelo confronto com o sofrimento do outro. A confrontação com o real da vulnerabilidade humana solicita o engajamento do corpo erótico em modalidades expressivas e afetivas, alterando-o. Nesse sentido, a compaixão deveria ser reconhecida como um trabalho. Mas, confundido com o corpo e com a afetividade, este trabalho desaparece (MOLINIER, 2002). Fortalecida pelas contribuições da sociologia das relações de sexo, a análise das situações de trabalho pela abordagem da psicodinâmica possibilita assumir uma postura crítica contrária à 
ocultação do trabalho das mulheres e, em consequência, contribuir para minimizar o déficit crônico de reconhecimento que elas sofrem.

\section{Referências}

DEJOURS, C.; ABDOUCHELI, E. Itinerário teórico em psicopatologia do trabalho. In: DEJOURS, C.; ABDOUCHELI, E.; JAYET, C. Psicodinâmica do trabalho: contribuições da Escola Dejouriana à análise da relação prazer, sofrimento e trabalho. São Paulo: Atlas, 1994. p. 119-145.

DEJOURS, C. Addendum - Da psicopatologia à psicodinâmica do trabalho. In: LANCMAN, S.; SZNELWAR, L. I. (Org.). Da psicopatologia à psicodinâmica do trabalho. Rio de Janeiro: Fiocruz, Brasília: Paralelo 15, 2008. p. 127-139.

DEJOURS, C. Trabalho vivo (tomo I): sexualidade e trabalho. Brasília: Paralelo 15, 2012.

HIRATA, H.; KERGOAT, D. Rapports sociaux de sexe e psychopathologie du travail. Travailler, v. 37, n. 1, p. 163-203, 2017/1. Cross ${ }^{\text {Ref. }}$

HIRATA, H.; KERGOAT, D. Novas configurações da divisão sexual do trabalho. Cadernos de Pesquisa, São Paulo, v. 37, n. 132, p. 595-609, set./dez. 2007. Cross ${ }^{\text {Ref. }}$

KERGOAT, D. Em defesa de uma sociologia das relações sociais: da análise das categorias dominantes à elaboração de uma nova conceituação. In: KARTCHEVSKY, A. et. al. (Colab.) O sexo do trabalho. Rio de Janeiro: Paz e Terra, 1986. p. 79-93.

KERGOAT, D. Divisão sexual do trabalho e relações sociais de sexo. In: HIRATA, H. et al. (Org.). Dicionário crítico do feminismo. São Paulo: Unesp, 2009. p. 67-75.

MOLINIER, P. Autonomie morale subjective et construction de l'identité sexuelle: l'apport de la psychodynamique du travail. Revue Internationale de Psychosociologie, v. 3, n. 5, p. 53-62, 1996.

MOLINIER, P. Psicodinâmica do trabalho e relações sociais de sexo: um itinerário interdisciplinar (1988-2002). Production, São Paulo, v. 14, n. 3, p. 14-26, set./dez. 2004. Cross ${ }^{\text {Ref. }}$

MOLINIER, P. Féminité sociale et construction de l'identité sexuelle: perspectives théoriques et cliniques en psychodynamique du travail. L'orientation scolaire et professionnelle, v. 31, n. 4, p. 565-580, 2002. Cross ${ }^{\text {Ref. }}$

Recebido em: 2 de junho de 2017

Aceito em: 15 de dezembro de 2017 